\title{
On-Site Visual Detection of Hydrogen Sulfide in Air Based on Enhancing the Stability of Gold Nanoparticles
}

\author{
Zhiyang Zhang, ${ }^{\dagger, \ddagger}$ Zhaopeng Chen, ${ }^{* \dagger \dagger}$ Shasha Wang, ${ }^{\dagger, \dagger}$ Chengli Qu, ${ }^{\dagger}$ and Lingxin Chen ${ }^{* \dagger}$
}

${ }^{\dagger}$ Key Laboratory of Coastal Environmental Processes and Ecological Remediation, Yantai Institute of Coastal Zone Research (YIC), Chinese Academy of Sciences (CAS); Shandong Provincial Key Laboratory of Coastal Environmental Processes, YICCAS, Yantai, Shandong 264003, P. R. China

${ }^{\ddagger}$ University of Chinese Academy of Sciences, Beijing 100049, China

\section{Supporting Information}

\begin{abstract}
We have described a simple and low-cost visual method for on-site detection of hydrogen sulfide $\left(\mathrm{H}_{2} \mathrm{~S}\right)$ in air based on the antiaggregation of gold nanoparticles (AuNPs). The bubbling of $\mathrm{H}_{2} \mathrm{~S}$ into a weak alkaline buffer solution leads to the formation of $\mathrm{HS}^{-}$, which can stabilize the AuNPs and ensure the AuNPs maintain their red color even in a Tris buffer solution containing $80 \mathrm{mM} \mathrm{NaCl}$ with the presence of Tween 80. The stabilization of the AuNPs is attributed to the adsorption of negatively charged $\mathrm{S}^{2-}$ on the AuNPs surface. In contrast, without the bubbling of $\mathrm{H}_{2} \mathrm{~S}$, AuNPs aggregate and change color from red to blue. Under optimal conditions, the proposed method exhibits excellent visual sensitivity with a naked-eye detectable limit of $0.5 \mathrm{ppm}(\mathrm{v} / \mathrm{v})$, making the on-site detection of $\mathrm{H}_{2} \mathrm{~S}$ possible. This method also possesses good selectivity toward $\mathrm{H}_{2} \mathrm{~S}$ over other gases by using a simple $\mathrm{SO}_{2}$ removal

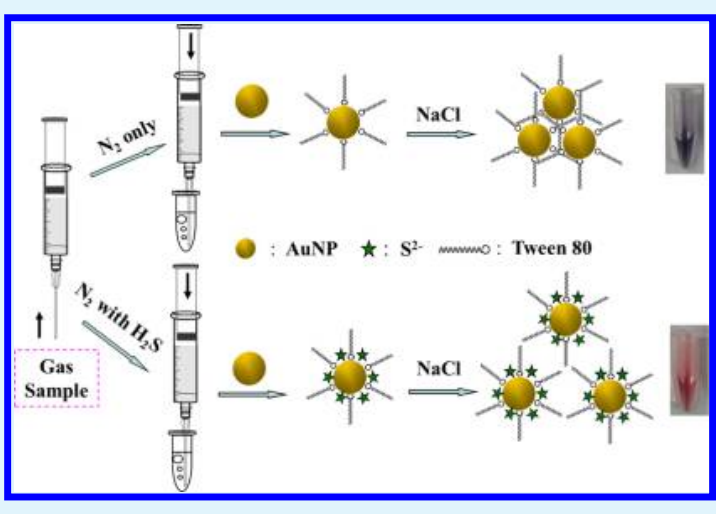
device. The successful determination of the concentrations of $\mathrm{H}_{2} \mathrm{~S}$ in local air indicates the potential application of this costeffective method.
\end{abstract}

KEYWORDS: hydrogen sulfide, visual detection, gold nanoparticles, stability

\section{INTRODUCTION}

Hydrogen sulfide $\left(\mathrm{H}_{2} \mathrm{~S}\right)$, a colorless, flammable, and highly toxic gas with a "rotten egg" odor, occurs naturally in crude petroleum, natural gas, and hot springs. ${ }^{1} \mathrm{H}_{2} \mathrm{~S}$ is also often produced by human activities, including petroleum/natural gas drilling and refining, and wastewater treatment. ${ }^{1}$ Exposure to $\mathrm{H}_{2} \mathrm{~S}$ can cause blood poisoning and even death at high concentrations (higher than $250 \mathrm{ppm}$ ). ${ }^{2,3}$ The occupational exposure limit of $\mathrm{H}_{2} \mathrm{~S}$ recommended by the US National Institute for Occupational Safety and Health is 10 ppm (ppm) for $8 \mathrm{~h}^{4}$ Therefore, to ensure the safety of workers, it is essential to develop appropriate methods for the monitoring of $\mathrm{H}_{2} \mathrm{~S}$, especially for on-site real-time monitoring.

The great progress has been made regarding $\mathrm{H}_{2} \mathrm{~S}$ sensor devices in the past several years. Generally, the devices can be divided into three major categories: semiconductor metal oxide (SMO), ${ }^{5,6}$ electrochemical, ${ }^{7,8}$ and optical sensors., ${ }^{9,10}$ SMO sensors are based on the resistance change aroused by the target gas. ${ }^{11}$ Although conventional SMO sensors have the advantages of simple design and fast response, they often consume watts of power, which makes personal and mobile monitoring difficult. ${ }^{5}$ Electrochemical sensors, utilizing amperometric or potentiometric signal, exhibit good sensitivity and short response time. However, they are readily affected by temperature and humidity. ${ }^{12}$ Most optical sensors, which operate on the principle of absorption or emission of photons, are not affected by temperature or humidity, but they often need an optical detector, which makes them large and expensive. ${ }^{5}$ Among the optical sensors, colorimetric sensors have attracted a growing reseach interests. Colorimetric sensors can eliminate or minimize costs associated with instrumentation and operation in detection, making them easily applicable to on-site detection. ${ }^{13}$ Thus, many colorimetric sensors have been reported for the detection of $\mathrm{H}_{2} \mathrm{~S}$ recently. ${ }^{14-22}$ Few of them, however, have been applied to the sensing of $\mathrm{H}_{2} \mathrm{~S}$ in air samples.

Gold nanoparticles (AuNPs) have a wide application in colorimetric assays because of their excellent distance-dependent optical property and high extinction coefficient in the visible region. ${ }^{23-25}$ AuNPs-based colorimetric sensors have been used for sensing a wide range of targets, such as proteins, ${ }^{26,27}$ oligonucleotides, ${ }^{28-30}$ metal ions, ${ }^{13,31}$ anions, ${ }^{32,33}$ and some small molecules. $^{26,34}$ Regrettably, few of them have been applied to the detection of pollutants in a gas sample. The main reasons, we consider, are the following: 1) the concentrations of gas pollutants are often as low as ppm levels, requiring highly sensitive sensors; 2) gas detection requires the efficient capture of targets from the gas sample into a aqueous solution in

Received: October 27, 2013

Accepted: April 22, 2014

Published: April 22, 2014 
advance; 3 ) the capture procedure may need a large volume of gas sample, and it is time-consuming; and 4) the property of the captured liquid may be not suitable for the colorimetric sensing condition (e.g., $\mathrm{pH}$ ). Therefore, solving these problems will be the key to the development of AuNPs-based colorimetric sensors for gas pollutants.

It is well-known that gold has a good affinity to sulfide with a stability constant of $2 \times 10^{36}$. 35,36 The high affinity between $\mathrm{Au}$ and $S$ was also certified by the $S\left(2 p_{3 / 2}\right)$ bonding energy (162.6 $\mathrm{eV}$ ) measured in the gold sulfide nanoparticles. ${ }^{37,38}$ Inspired by this property, herein, we have designed a label-free colorimetric sensor for the on-site detection of $\mathrm{H}_{2} \mathrm{~S}$ in a gas sample based on enhancing the stability of AuNPs. Under high ionic strength, AuNPs aggregate and change color from red to blue. Once $\mathrm{H}_{2} \mathrm{~S}$ is bubbled into the weak buffer, the reaction between the formed hydrosulfide ions and AuNPs in the presence of dissolved oxygen will result in the absorption of $\mathrm{S}^{2-}$ on AuNPs. The absorbed negatively charged $\mathrm{S}^{2-}$ ions prevent the aggregation of AuNPs, maintaining the wine red color of the AuNPs. The proposed method exhibits high sensitivity with a visual detection limit of $0.5 \mathrm{ppm}$ for $\mathrm{H}_{2} \mathrm{~S}$ with bubbling of only $10 \mathrm{~mL}$ sample volume and a good selectivity toward $\mathrm{H}_{2} \mathrm{~S}$.

\section{EXPERIMENTAL SECTION}

Reagents. Hydrogen tetrachloroaurate(III) dehydrate $\left(\mathrm{HAuCl}_{4}\right)$, trisodium citrate, tris(hydroxymethyl)aminomethane (Tris), $\mathrm{NaOH}$, $\mathrm{Na}_{2} \mathrm{SO}_{4}, \mathrm{NaNO}_{3}, \mathrm{Na}_{2} \mathrm{CO}_{3}, \mathrm{NaF}, \mathrm{NaCl}, \mathrm{Na}_{2} \mathrm{~S}, \mathrm{CH}_{3} \mathrm{COOH}$, $\mathrm{CH}_{3} \mathrm{CH}_{2} \mathrm{OH}, \mathrm{HCHO}, \mathrm{CH}_{3} \mathrm{OH}$, and Tween $80,60,40$, and 20 were obtained from Sinopharm Chemical Reagent (China). $\mathrm{CH}_{3} \mathrm{SH}$ was obtained from Aladdin reagent. The $\mathrm{N}_{2}$-diluted $\mathrm{H}_{2} \mathrm{~S}$ and $\mathrm{CO}_{2}$ standard gases were purchased from Yantai Feiyuan Comprehensive Management Services Company (China), and the air bags were purchased from Guangming Research \& Design Institute of Chemical Industry (China). The $\mathrm{NO}_{2}, \mathrm{Cl}_{2}$, and $\mathrm{SO}_{2}$ gases were synthesized in the laboratory, the procedure for which is shown in the Supporting Information. All solutions were prepared with deionized water (18.2 $\mathrm{M} \Omega \cdot \mathrm{cm}$ specific resistance) obtained with a Pall Cascada laboratory water system.

Apparatus. UV-vis absorption spectra were measured on a Thermo Scientific NanoDrop 2000/2000C spectrophotometer (USA). Size distribution measurements were performed on a Malvern Zeta/ sizer Nano-ZS90 (ZEN3590). Transmission electron microscopy (TEM) analyses were performed on a JEM-1230 electron microscope (Japan) operating at $100 \mathrm{kV}$.

Making of Mini Silica Gel Absorption Column for $\mathrm{SO}_{2}$ Removal. Silicon dioxide powder $(300 \mathrm{mesh})$ was filled in a polystyrene tube (length $6 \mathrm{~cm}$, diameter $0.5 \mathrm{~cm}$ ), and the two ends of the tube were filled tightly with cotton.

Making of Mini Silica Gel Absorption Column for $\mathrm{H}_{2} \mathrm{~S}$ Removal. Wet $\mathrm{CuSO}_{4} \cdot 5 \mathrm{H}_{2} \mathrm{O}$ was filled in a polystyrene tube (length 6 $\mathrm{cm}$, diameter $0.5 \mathrm{~cm}$ ), and the two ends of the tube were filled tightly with cotton.

Synthesis and Characterization of the AuNPs. A $13 \mathrm{~nm}$ diameter gold nanoparticle colloid was synthesized based on the reported method. ${ }^{39}$ Simply, $2 \mathrm{~mL}$ of $\mathrm{HAuCl}_{4}(50 \mathrm{mM})$ was added to $98 \mathrm{~mL}$ of deionized water under vigorous stirring. After the solution was heated and refluxed to boiling, $10 \mathrm{~mL}$ of sodium citrate $(38.8$ $\mathrm{mM}$ ) was then quickly added. Reflux was kept for another 20 min until the solution color had changed from pale yellow to wine red.

The as-prepared AuNPs were characterized by TEM images (see "Sensing mechanism" section) and UV-vis spectra (see Figure S1 in the Supporting Information). The original concentration of AuNPs is approximately $10 \mathrm{nM}$ according to the extinction coefficient $\left(2.7 \times 10^{8}\right.$ $\mathrm{M}^{-1} \mathrm{~cm}^{-1}$ ) for $13 \mathrm{nM}$ AuNPs. ${ }^{40}$

Colorimetric Detection of $\mathrm{H}_{2} \mathrm{~S}$. The procedure of $\mathrm{H}_{2} \mathrm{~S}$ sensing was conducted at room temperature as shown in the flowchart (see Figure S2 in the Supporting Information). First, a $10 \mathrm{~mL}$ gas sample was drawn into a plastic syringe and was slowly bubbled into an 800 $\mu \mathrm{L}$ Tris buffer solution $(50 \mathrm{mM}, \mathrm{pH} 8.0)$ containing Tween 80 $(0.015 \%(\mathrm{v} / \mathrm{v}))(\mathrm{TBST})$ manually within $1 \mathrm{~min}$. Second, a $200 \mu \mathrm{L}$ AuNPs solution $(10 \mathrm{nM})$ was added into the solutions above, and the mixed solutions were incubated for $8 \mathrm{~min}$, followed by the injection of $40 \mu \mathrm{L}$ of $\mathrm{NaCl}(2 \mathrm{M})$. After incubation for $7 \mathrm{~min}$, the resulting solutions were subjected to UV-vis absorption spectra measurements.

Analysis of $\mathrm{H}_{2} \mathrm{~S}$ in Real Samples. A series of samples was prepared in air bags by spiking a standard gas of $\mathrm{H}_{2} \mathrm{~S}$ with the clear local air. It was necessary to filter the local air if the content of the suspended particles in the air was high. To detect the concentration of $\mathrm{H}_{2} \mathrm{~S}$ in the real samples, a similar test was adopted as in the above assay process.

\section{RESULTS AND DISCUSSION}

Sensing Mechanism. Figure 1A shows schematically the mechanism for $\mathrm{H}_{2} \mathrm{~S}$ detection. First, a $10 \mathrm{~mL}$ gas sample

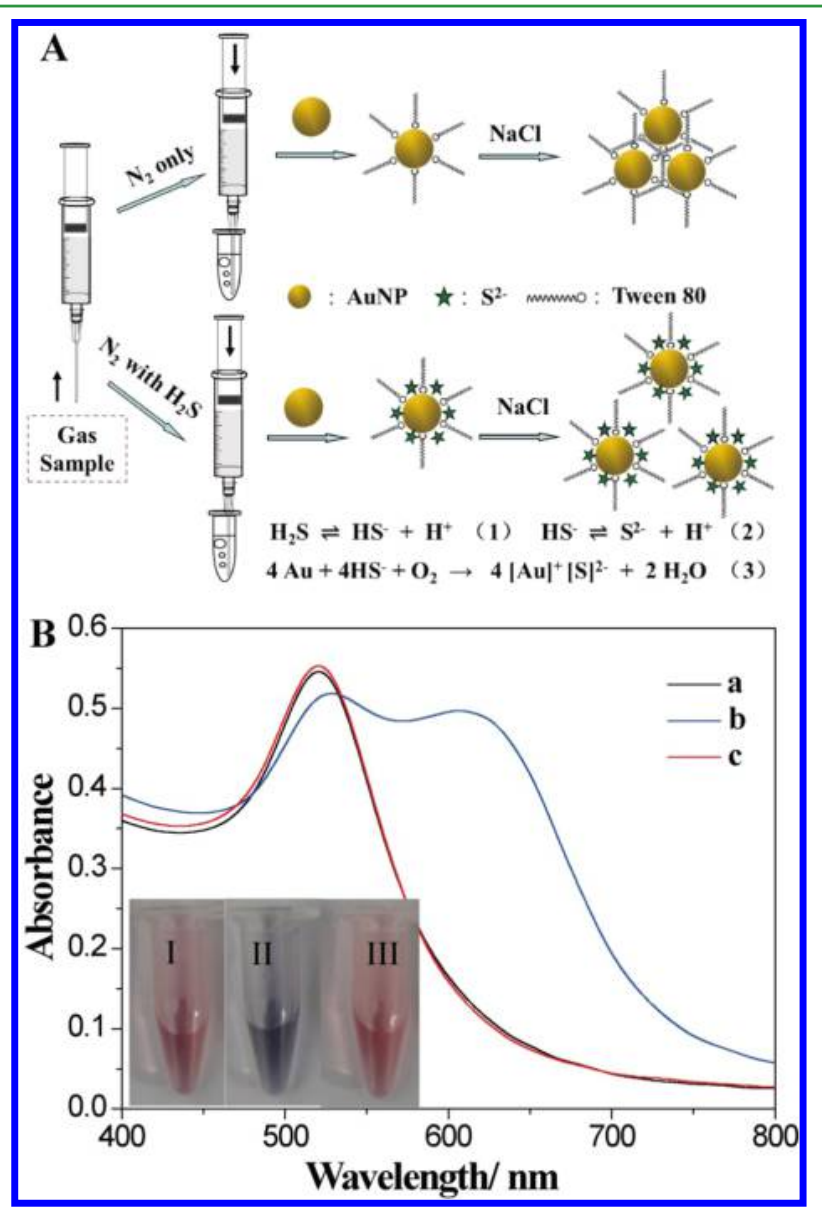

Figure 1. (A) Schematic description of the mechanism for sensing gaseous $\mathrm{H}_{2} \mathrm{~S}$; (B) UV-vis spectra and colors of AuNPs in TBST before (a, I) and after the addition of $\mathrm{NaCl}$ without (b, II) and with (c, III) prebubbling of $10 \mathrm{~mL}$ of $\mathrm{H}_{2} \mathrm{~S}(3 \mathrm{ppm})$.

containing $\mathrm{H}_{2} \mathrm{~S}$ or not was drawn into a plastic syringe and was slowly bubbled into TBST by hand. Second, the AuNPs were added as the indicator. The AuNPs stayed red in both samples with a typical absorption at $520 \mathrm{~nm}$ (digital photograph I and curve a in Figure 1B). However, the further addition of $40 \mu \mathrm{L}$ of $\mathrm{NaCl}(2 \mathrm{M})$ resulted in different phenomena. The color of the solution without bubbling of $\mathrm{H}_{2} \mathrm{~S}$ changed from red to blue (digital photograph II in Figure 1B), accompanied by a red shift of the surface plasmon resonance (SPR) absorption (curve $b$ in Figure $1 \mathrm{~B}$ ) due to the aggregation of AuNPs. In contrast, the 


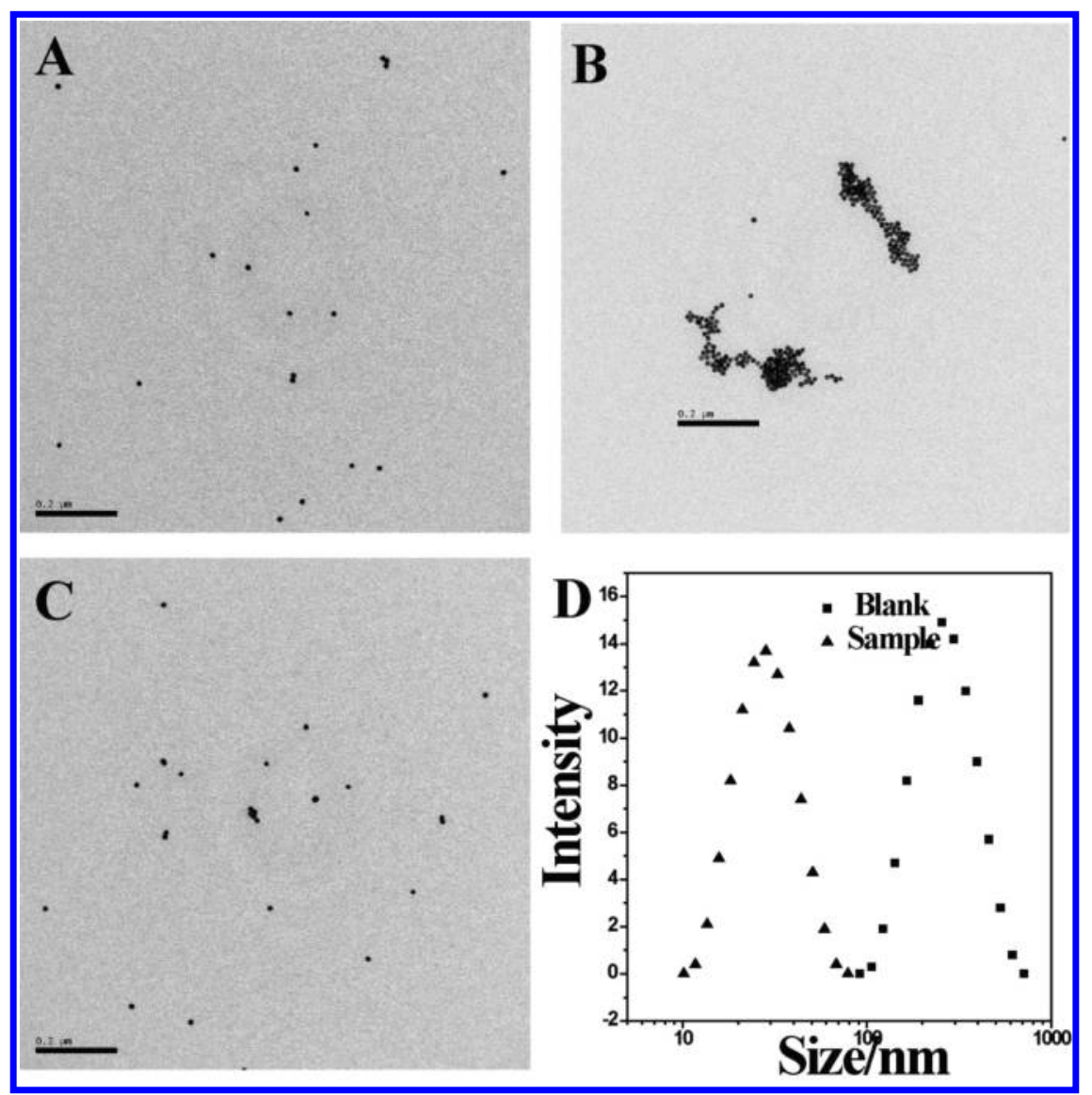

Figure 2. TEM images: AuNPs dispersed in pure water (A), AuNPs in TBST without (B), and with (C) the prebubbling of $10 \mathrm{~mL}$ of $\mathrm{H}_{2} \mathrm{~S}(3 \mathrm{ppm})$ after adding $\mathrm{NaCl}$; DLS measurements (D) for AuNPs without and with $(\boldsymbol{\Delta})$ the prebubbling of $10 \mathrm{~mL}$ of $\mathrm{H}_{2} \mathrm{~S}$ (3 ppm).

color of the solution with the bubbling of $\mathrm{H}_{2} \mathrm{~S}$ stayed red with an absorption peak at approximately $520 \mathrm{~nm}$ (digital photograph III and curve $c$ in Figure 1B), indicating the AuNPs were monodispersed in TBST. The aggregation of AuNPs was further confirmed by the comparison of the TEM images and DLS data with and without the bubbling of $\mathrm{H}_{2} \mathrm{~S}$. Similar to the AuNPs in pure water (Figure 2A), the AuNPs were also monodispersed in TBST with the prebubbling of $\mathrm{H}_{2} \mathrm{~S}$ (Figure 2C) after the further addition of $\mathrm{NaCl}$. The TEM image $\mathrm{B}$ demonstrated that the AuNPs aggregated in TBST without the prebubbling of $\mathrm{H}_{2} \mathrm{~S}$ after the further addition of $\mathrm{NaCl}$. These results were also consistent with the DLS data, as shown in Figure 2D. The DLS data showed that the number of large particles with the prebubbling of $\mathrm{H}_{2} \mathrm{~S}$ decreased compared to that without the prebubbling of $\mathrm{H}_{2} \mathrm{~S}$. The large particles in TBST were attributed to the aggregation of AuNPs, indicating the prebubbling of $\mathrm{H}_{2} \mathrm{~S}$ into TBST enhanced the stability of AuNPs (Figure 2D).

$\mathrm{H}_{2} \mathrm{~S}$ can dissolve efficiently in the weak alkaline TBST with a solubility of no less than $0.33 \mathrm{~g} / 100 \mathrm{~g}(0.097 \mathrm{M})$ and exists mainly as hydrosulfide ions $\left(\mathrm{HS}^{-}\right) .^{41}$ Once the AuNPs were added to the above solution, the $\mathrm{Au}$ atoms on the surface of the AuNPs reacted with dissolved oxygen in the presence of $\mathrm{HS}^{-}$ ions and produced $\left[\mathrm{Au}^{+}\right]\left[\mathrm{S}^{2-}\right]$ on the surface of the AuNPs (chemical reaction (3) in Figure 1A). At the same time, $\mathrm{S}^{2-}$ and $\mathrm{H}_{2} \mathrm{~S}$ transformed into $\mathrm{HS}^{-}$. Because of the high affinity between $\mathrm{Au}$ and $\mathrm{S}$, negatively charged $\mathrm{S}^{2-}$ was firmly adsorbed on the surface of the AuNPs and significantly enhanced their stability due to electrostatic repulsion. As a result, the AuNPs remained monodispersed in solution and remained red in color under high ionic strength (Figure 1B).

To further prove $\mathrm{S}^{2-}$ was absorbed on AuNPs, the solution was subject to Raman spectra measurements with the presence and absence of $\mathrm{Na}_{2} \mathrm{~S}$. As shown in Figure 3,1 $\mathrm{mM} \mathrm{Na}_{2} \mathrm{~S}$ in a

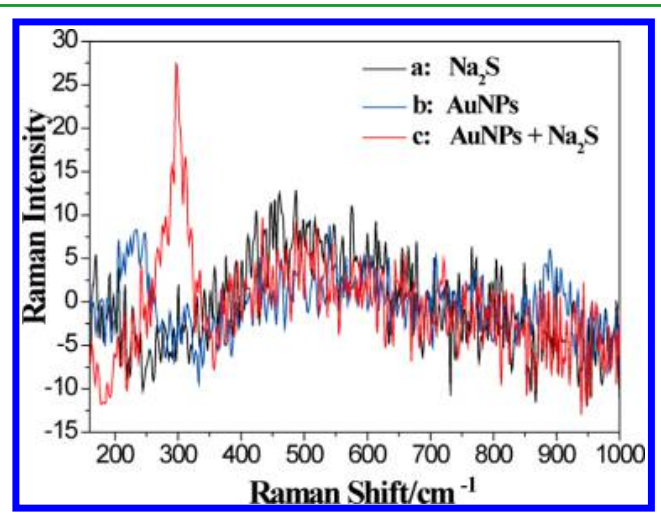

Figure 3. Raman spectra of $1.0 \mathrm{mM} \mathrm{Na}_{2} \mathrm{~S}(\mathrm{a})$, AuNPs (b), and AuNPs with $1.0 \mathrm{mM} \mathrm{Na}_{2} \mathrm{~S}$ (c) in the Tris buffer solution ( $\mathrm{pH} \mathrm{8.0)}$.

Tris solution without the addition AuNPs did not generate any featured Raman peaks (curve a). The addition of AuNPs to the Tris solution caused a very weak peak at approximately 232 $\mathrm{cm}^{-1}$ (curve b). This Raman peak may be attributed to the Au$\mathrm{N}$ stretching ${ }^{42,43}$ because of the interaction between $\mathrm{Au}$ and the $\mathrm{N}$ atom of Tris. In the copresence of $\mathrm{Na}_{2} \mathrm{~S}$ and AuNPs, a broad peak from 260 to $320 \mathrm{~cm}^{-1}$ appeared, and the peak at 


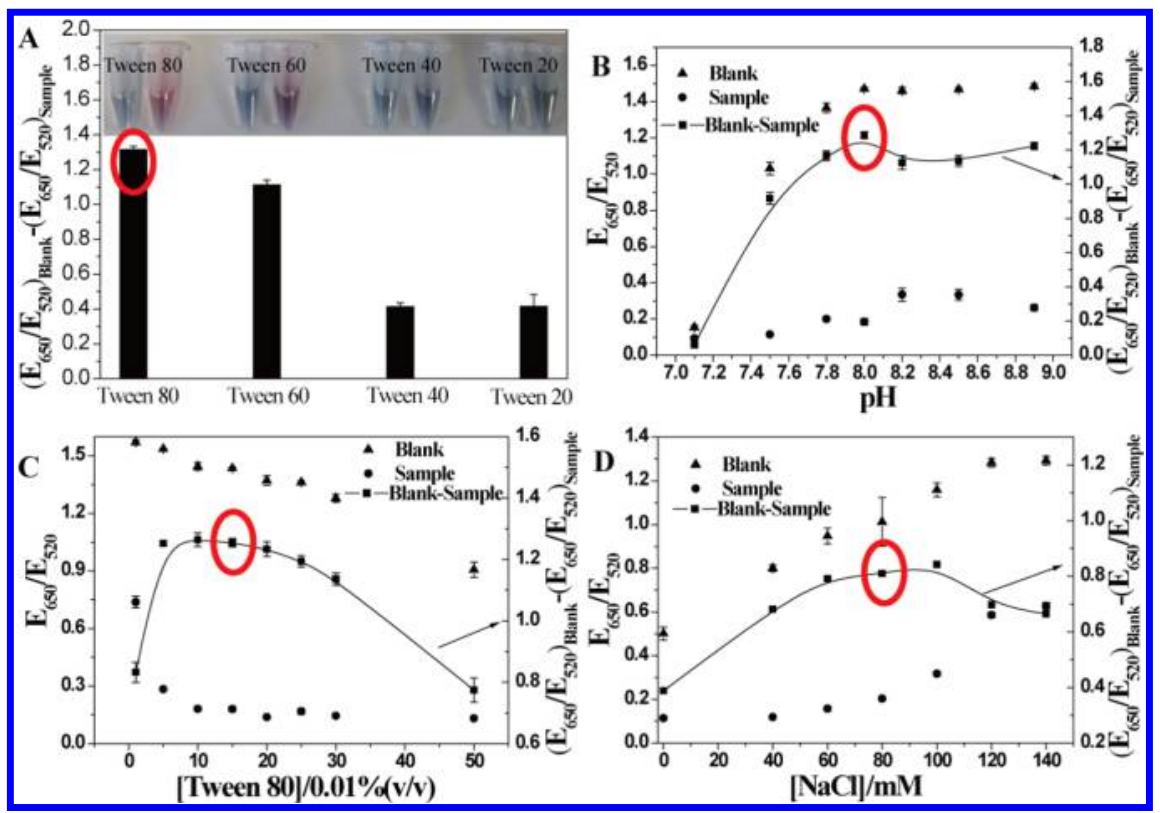

Figure 4. Optimization of experimental conditions: (A) Effect of Tween 80, Tween 60, Tween 40, and Tween 20 on the value of $\left(\mathrm{E}_{650} / \mathrm{E}_{520}\right)_{\mathrm{Blank}}$ $\left(\mathrm{E}_{650} / \mathrm{E}_{520}\right)_{\text {Sample }}$ and their corresponding color in the absence (right) and presence (left) of $\mathrm{Na}_{2} \mathrm{~S}$; Effects of $(\mathrm{B}) \mathrm{pH}$, concentration of (C) Tween 80 and (D) $\mathrm{NaCl}$ on the ratio of $\left(\mathrm{E}_{650} / \mathrm{E}_{520}\right)_{\text {Blank }}(\boldsymbol{\Delta}),\left(\mathrm{E}_{650} / \mathrm{E}_{520}\right)_{\text {Sample }}(\boldsymbol{\bullet})$ and the value of $\left(\mathrm{E}_{650} / \mathrm{E}_{520}\right)_{\text {Blank }}-\left(\mathrm{E}_{650} / \mathrm{E}_{520}\right)_{\text {Sample }}(\boldsymbol{\square})$. The lines are the mathematical fits and were used to represent the change trend of $\left(\mathrm{E}_{650} / \mathrm{E}_{520}\right)_{\text {Blank }}-\left(\mathrm{E}_{650} / \mathrm{E}_{520}\right)_{\text {Sample }}$. Experimental conditions: The concentration of $\mathrm{Na}_{2} \mathrm{~S}$ is $1.0 \mu \mathrm{M}$ in (A), (B), (C) and $0.5 \mu \mathrm{M}$ in (D).

approximately $232 \mathrm{~cm}^{-1}$ disappeared (curve c). The broad peak could be explained by the gold-monatomic sulfur stretching reported elsewhere. ${ }^{44,45}$ Additionally, the disappearance of the peak at $232 \mathrm{~cm}^{-1}$ can be explained by the displacement of Tris molecules by $\mathrm{S}^{2-}$ because Au has a larger affinity with $\mathrm{S}$ than $\mathrm{N}$. Therefore, we conclude that the $S^{2-}$ actually adsorbs onto the gold nanoparticles.

In addition, some other control experiments laterally proved the mechanism. It has been reported that some other anions, such as $\mathrm{I}^{-}, \mathrm{SCN}^{-}$, and $\mathrm{S}_{2} \mathrm{O}_{3}{ }^{2-}$, also have a strong affinity with $\mathrm{Au}$ and could adsorb onto the surface of AuNPs. ${ }^{33,46,47}$ Thus, we reason that these anions may also have a similar property as $\mathrm{S}^{2-}$. As described in Figure S3 in the Supporting Information, the AuNPs in TBST with the addition of $1.0 \mu \mathrm{M} \mathrm{I}^{-}, 1.0 \mu \mathrm{M}$ $\mathrm{SCN}^{-}$, and $10 \mu \mathrm{M} \mathrm{S}_{2} \mathrm{O}_{3}{ }^{2-}$ exhibited a typical extinction band at $520 \mathrm{~nm}$ in the UV-vis spectra even after the addition of $\mathrm{NaCl}$. The results further confirmed that the adsorption of the negatively charged anions significantly enhanced the stability of the AuNPs.

In the absence of Tween 80 , the sulfide alone could also enhance the stability of the AuNPs. As shown in Figure S4 in the Supporting Information, the AuNPs aggregated in the Tris buffer solution without $\mathrm{Na}_{2} \mathrm{~S}$, while the AuNPs remained monodispersed in the presence of $\mathrm{Na}_{2} \mathrm{~S}$. Although the phenomenon can be used for the detection of $\mathrm{H}_{2} \mathrm{~S}$ directly, our preliminary experimental results showed that the detection limit was relatively high $(10 \mathrm{ppm})$. The detection limit could be improved significantly by the addition of Tween 80 . We speculated the function of Tween 80 in the sensing system was exhibited in two aspects. First, the presence of Tween 80 produced lots of foam in the process of bubbling the gas into the Tris buffer solution, inhibiting the escape of $\mathrm{H}_{2} \mathrm{~S}$ from aqueous solution and, therefore, increased the contact time between $\mathrm{H}_{2} \mathrm{~S}$ and the weak alkaline buffer solution. Thus, the absorption efficiency of $\mathrm{H}_{2} \mathrm{~S}$ was improved. Second, Tween 80 enhanced the stability of the AuNPs and, therefore, extended the time of the chemical reaction (3), as shown in Figure 1A. The extension of the reaction time increased the $\mathrm{S}^{2-}$ adsorption onto the AuNPs before autoaggregation in the Tris buffer solution.

Optimization of Experimental Conditions. As proved above, the mechanism is intrinsic to detect dissolved sulfide. To simplify the experiment, we used the addition of $\mathrm{Na}_{2} \mathrm{~S}$ to replace the bubbling of $\mathrm{H}_{2} \mathrm{~S}$ to optimize the experimental conditions. Because the extinction bands of the solution at 650 and $520 \mathrm{~nm}$ in the UV-vis absorption spectrum correspond to the quantities of the dispersed and aggregated AuNPs, ${ }^{40}$ respectively, the ratio of the extinction at $650 \mathrm{~nm}$ to that at 520 $\mathrm{nm}\left(\mathrm{E}_{650} / \mathrm{E}_{520}\right)$ has been chosen to express the degree of aggregation of the AuNPs. Similarly, $\left(\mathrm{E}_{650} / \mathrm{E}_{520}\right)_{\mathrm{Blank}}$ and $\left(\mathrm{E}_{650} /\right.$ $\left.E_{520}\right)_{\text {Sample }}$ are used to express the degree of aggregation of the AuNPs in the absence and presence of $\mathrm{Na}_{2} \mathrm{~S}$, respectively. Because AuNPs with different degrees of aggregation exhibit different colors, the value of the difference between $\left(\mathrm{E}_{650} /\right.$ $\left.\mathrm{E}_{520}\right)_{\text {Blank }}$ and $\left(\mathrm{E}_{650} / \mathrm{E}_{520}\right)_{\text {Sample }}$ indicates the difference in color in the AuNPs solutions between the absence and the presence of $\mathrm{Na}_{2} \mathrm{~S}$. Using this parameter, we have explored the effects of surfactants with different chain lengths, $\mathrm{pH}$, and concentrations of surfactants and $\mathrm{NaCl}$.

We first investigated the effect of surfactant chain length on the detection of $\mathrm{Na}_{2} \mathrm{~S}$. As shown in Figure 4A, the values of $\left(\mathrm{E}_{650} / \mathrm{E}_{520}\right)_{\text {Blank }}-\left(\mathrm{E}_{650} / \mathrm{E}_{520}\right)_{\text {Sample }}$ in groups of Tween 80 and Tween 60 were much larger than that in groups of Tween 40 and Tween 20. This result occurs because the longer surfactant chain length could provide a larger steric hindrance among AuNPs, leading to a stronger ability to prevent the AuNPs aggregation. As the photographs in Figure 4A show, the most obvious color difference between the blank and the sample was observed in the Tween 80 group; thus, we chose Tween 80 as the surfactant in our experiments.

Figure $4 \mathrm{~B}$ shows the effect of $\mathrm{pH}$ on $\left(\mathrm{E}_{650} / \mathrm{E}_{520}\right)_{\mathrm{Blank}}-\left(\mathrm{E}_{650} /\right.$ $\left.\mathrm{E}_{520}\right)_{\text {Sample }}$. With the increase of $\mathrm{pH}$ from 6.8 to 7.8 , the value of 
$\left(\mathrm{E}_{650} / \mathrm{E}_{520}\right)_{\mathrm{Blank}}$ increased sharply. The increase in $\mathrm{pH}$ increased the concentration of the neutral Tris molecules, which displaced the citrate adsorbed on the AuNPs and led to the aggregation of AuNPs. ${ }^{48}$ In contrast, the value of $\left(\mathrm{E}_{650} /\right.$ $\left.\mathrm{E}_{520}\right)_{\text {Sample }}$ changed less significantly. This result occurred because the adsorption of negatively charged $\mathrm{S}^{2-}$ on the surface of the AuNPs not only prevented the attack of Tris molecules but also enhanced the stability of AuNPs in the whole $\mathrm{pH}$ range. When the $\mathrm{pH}$ was increased to 8.0, the value of $\left(\mathrm{E}_{650} / \mathrm{E}_{520}\right)_{\text {Blank }}-\left(\mathrm{E}_{650} / \mathrm{E}_{520}\right)_{\text {Sample }}$ reached its maximum. Therefore, a $\mathrm{pH}$ of 8.0 was selected.

Figures $4 \mathrm{C}$ and $\mathrm{D}$ describe the effects of the concentrations of Tween 80 and $\mathrm{NaCl}$ on the value of $\left(\mathrm{E}_{650} / \mathrm{E}_{520}\right)_{\mathrm{Blank}}$ and $\left(\mathrm{E}_{650} / \mathrm{E}_{520}\right)_{\text {Sample. }}$. As shown, $0.015 \%(\mathrm{v} / \mathrm{v})$ Tween 80 and 80 $\mathrm{mM} \mathrm{NaCl}$ should be selected, respectively.

Sensitivity. Before testing the sensitivity for $\mathrm{H}_{2} \mathrm{~S}$ in the gas sample, the sensitivity for $\mathrm{Na}_{2} \mathrm{~S}$ in aqueous solution was evaluated. The ratio of $\left[\left(\mathrm{E}_{650} / \mathrm{E}_{520}\right)_{\text {Blank }}-\left(\mathrm{E}_{650} / \mathrm{E}_{520}\right)_{\text {Sample }}\right] /$ $\left[\left(\mathrm{E}_{650} / \mathrm{E}_{520}\right)_{\text {Blank }}-\left(\mathrm{E}_{650} / \mathrm{E}_{520}\right)_{\text {Monodisperse AuNPs }}\right]$ is chosen to express the concentration of $\mathrm{Na}_{2} \mathrm{~S}$, and this mathematical expression is abbreviated as $\left[\left(\mathrm{E}_{650} / \mathrm{E}_{520}\right)_{\mathrm{Blank}}-\left(\mathrm{E}_{650} /\right.\right.$ $\left.\left.\mathrm{E}_{520}\right)_{\text {Sample }}\right] /$ Max. Different concentrations of $\mathrm{Na}_{2} \mathrm{~S}$ from 0 to $2 \mu \mathrm{M}$ were tested. The absorption spectra and color changes with the presence of different concentrations of $\mathrm{Na}_{2} \mathrm{~S}$ are shown in Figure S5 in the Supporting Information. A linear calibration graph was obtained in the range of $0.05-0.4 \mu \mathrm{M}$ for $\mathrm{Na}_{2} \mathrm{~S}$ (see Figure S5 in the Supporting Information). The detection limit was calculated to be $30 \mathrm{nM}$ according to the $3 \sigma$ rule $(\mathrm{n}=5$, see the Supporting Information).

As mentioned above, the sensing of $\mathrm{H}_{2} \mathrm{~S}$ is intrinsic for detecting dissolved sulfide; therefore, the highly sensitive detection for $\mathrm{Na}_{2} \mathrm{~S}$ provides a good prerequisite for sensing $\mathrm{H}_{2} \mathrm{~S}$ gas. The relation between the dissolved sulfide and gas sample is described here.

$$
\mathrm{C}_{d}=10^{-6} \eta\left(\mathrm{C}_{g} \cdot \mathrm{V}_{g} / \mathrm{V}_{m}\right) \div \mathrm{V}_{s}
$$

In eq $1, \mathrm{C}_{d}$ is the concentration of sulfide when $\mathrm{H}_{2} \mathrm{~S}$ was dissolved in buffer solution, M; $\eta$ is the efficiency of the $\mathrm{H}_{2} \mathrm{~S}$ capture; $\mathrm{C}_{g}$ is the concentration of $\mathrm{H}_{2} \mathrm{~S}$ in the gas sample, ppm; $\mathrm{V}_{g}$ is the gas sample volume, $\mathrm{mL} ; \mathrm{V}_{m}$ is the molar volume (20 $\left.{ }^{\circ} \mathrm{C}, 101 \mathrm{kpa}\right), 24.0 \mathrm{~L} \cdot \mathrm{mol}^{-1}$; and $\mathrm{V}_{s}$ is the volume of buffer solution for the $\mathrm{H}_{2} \mathrm{~S}$ capture, $\mathrm{mL}$.

Different concentrations of $\mathrm{H}_{2} \mathrm{~S}$ from 0 to $3 \mathrm{ppm}(\mathrm{v} / \mathrm{v})$ were spiked in pre-evacuated air bags, and $10 \mathrm{~mL}$ of the samples was bubbled into the Tris buffer solution. The dissolved sulfide was then detected according to the procedure as mentioned in the Experimental Section. As shown in Figure 5A, the extinction band at $650 \mathrm{~nm}$ decreased gradually with the increase in $\mathrm{H}_{2} \mathrm{~S}$ concentration from 0 to $3 \mathrm{ppm}$, and the corresponding color changed from blue to red (photograph in Figure 5A). The test results indicated that the average efficiency of the $\mathrm{H}_{2} \mathrm{~S}$ capture $(\eta)$ was approximately $75 \%$ (see Table $S 1$ in the Supporting Information) which is estimated by the calibration curve in Figure S5 in the Supporting Information. A linear calibration graph was obtained in the range of $0.1-1.5 \mathrm{ppm}$ for $\mathrm{H}_{2} \mathrm{~S}$ (Figure 5B). The detection limit using a spectrophotometer was calculated to be $0.08 \mathrm{ppm}$ according to the $3 \sigma$ rule $(\mathrm{n}=5)$. Compared to other conventional $\mathrm{H}_{2} \mathrm{~S}$ sensors (e.g., SMO sensors), ${ }^{2}$ this method has a longer response time (approximately $16 \mathrm{~min}$ ) and a higher detection limit, but the proposed method has the advantage of visual detection of $\mathrm{H}_{2} \mathrm{~S}$ without any instruments. This method exhibits a naked-eye-detectable

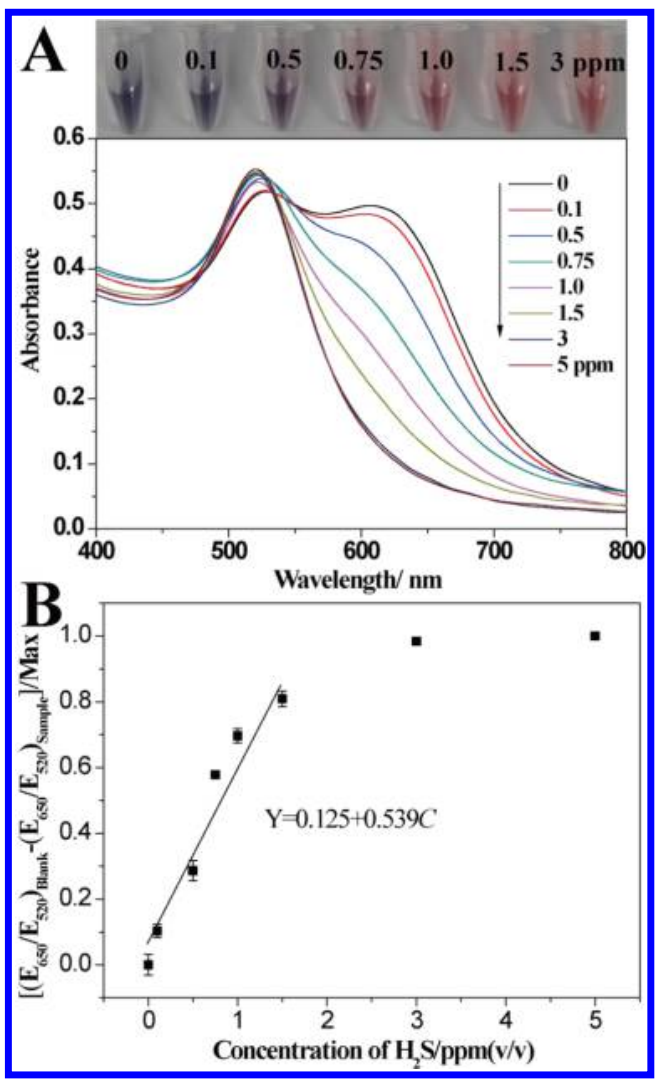

Figure 5. Photographs and UV-vis spectra of AuNPs with bubbling different concentrations of $\mathrm{H}_{2} \mathrm{~S}$ (A) and the plot of the calibration curve of $\left[\left(\mathrm{E}_{650} / \mathrm{E}_{520}\right)_{\text {Blank }}-\left(\mathrm{E}_{650} / \mathrm{E}_{520}\right)_{\text {Sample }}\right] /$ Max versus concentrations of $\mathrm{H}_{2} \mathrm{~S}(\mathrm{~B})$.

limit of $0.5 \mathrm{ppm}$ which is much lower than the limit recommended by the US National Institute for Occupational Safety and Health (10 ppm). Thus, it is suitable for on-site detection in the workplace. In addition, according to eq 1 , one can reason that the detection limit can be lowered if more gas sample volume is bubbled into the buffer solution. The experimental results supported our inference well. As Figure S6 in the Supporting Information shows, the sensitivity was improved when a $100 \mathrm{~mL}$ gas sample was bubbled into the analytical system.

Selectivity. Some control experiments were undertaken to evaluate the selectivity of the method. Judging from the detection procedure (see Figure S2 in the Supporting Information), the gases will dissolve fully in the buffer solution before the addition of the AuNPs solution, which means the essence of this probe is to detect dissolved sulfide. Therefore, to simplify the assay, some solutes, which are in the dissolved form when the corresponding gases are captured in the buffer, were used to test the selectivity. First, the gases $\mathrm{CO}_{2}, \mathrm{NO}_{2}, \mathrm{Cl}_{2}$, and $\mathrm{SO}_{2}$ were synthesized and tested. The test results indicated $\mathrm{SO}_{2}$ (3.0 ppm) could also lead to a strong false positive signal (see Figure S7 in the Supporting Information). To address the problem, a silica gel absorption column was made to selectively absorb $\mathrm{SO}_{2}$ (Figure 6A). ${ }^{49}$ As shown in Figure 6B, when the gas was passed through the system shown in Figure 6A, 10000 ppm of $\mathrm{SO}_{2}$ was absorbed completely, and no false positive signal was generated, while $3.0 \mathrm{ppm}$ of $\mathrm{H}_{2} \mathrm{~S}$ was hardly influenced, and a significant signal still existed. Second, the effects of other gases $\left(\mathrm{SO}_{3}, \mathrm{NH}_{3}, \mathrm{HF}, \mathrm{CH}_{3} \mathrm{COOH}\right.$, $\mathrm{CH}_{3} \mathrm{CH} 2 \mathrm{OH}, \mathrm{HCHO}, \mathrm{CH}_{3} \mathrm{OH}$, and $\mathrm{CH}_{3} \mathrm{SH}$ ) were tested by 


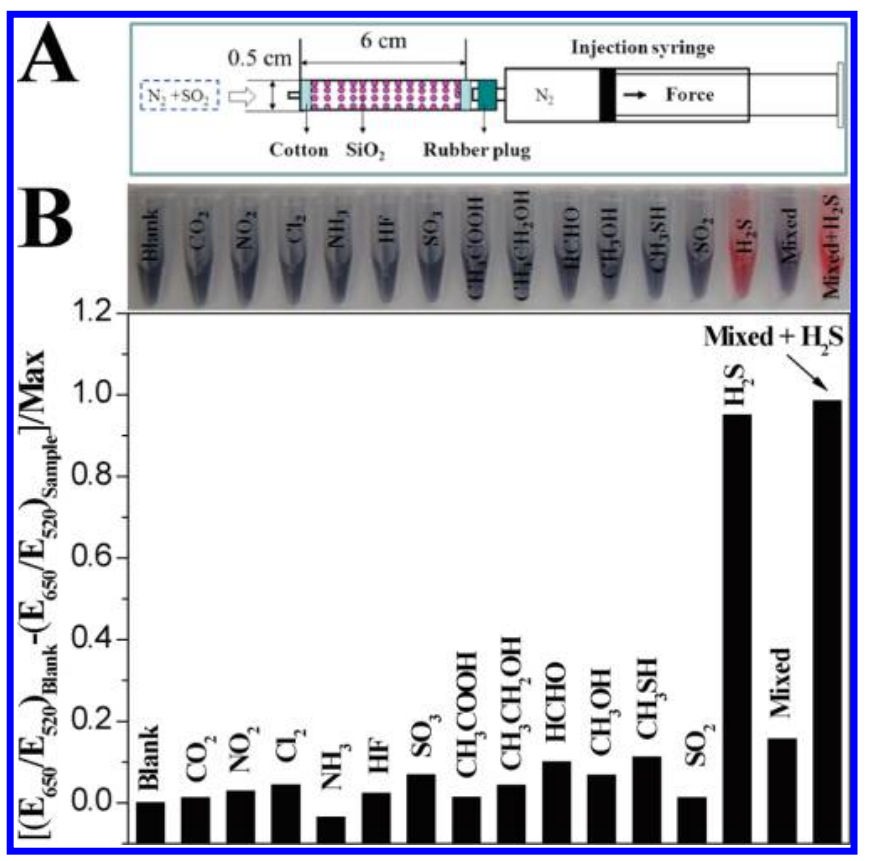

Figure 6. The system for selective absorption of $\mathrm{SO}_{2}(\mathrm{~A}) ;\left[\left(\mathrm{E}_{650} /\right.\right.$ $\left.\left.\mathrm{E}_{520}\right)_{\text {Blank }}-\left(\mathrm{E}_{650} / \mathrm{E}_{520}\right)_{\text {Sample }}\right] / \mathrm{Max}$ and photographs (inset) of the response of the AuNPs solutions to the prebubbling of $\mathrm{H}_{2} \mathrm{~S}$ gas (approximately equal to $1.0 \mu \mathrm{M} \mathrm{Na} 2 \mathrm{~S}$ ), $10000 \mathrm{ppm}$ of $\mathrm{SO}_{2}$ gas, 100 ppm $\left(\mathrm{CO}_{2}, \mathrm{NO}_{2}\right.$, and $\mathrm{Cl}_{2}$ gas) and $10.0 \mu \mathrm{M} \mathrm{NH}_{4}^{+}\left(\mathrm{NH}_{3}\right), \mathrm{F}^{-}(\mathrm{HF})$, $\mathrm{SO}_{4}{ }^{2-}\left(\mathrm{SO}_{3}\right), \mathrm{CH}_{3} \mathrm{COOH}, \mathrm{CH}_{3} \mathrm{CH}_{2} \mathrm{OH}, \mathrm{HCHO}, \mathrm{CH}_{3} \mathrm{OH}$ and 1.0 $\mu \mathrm{M} \mathrm{CH}_{3} \mathrm{SH}$, respectively (B).

using their dissolved forms $\left(\mathrm{SO}_{4}{ }^{2-}, \mathrm{NH}_{4}{ }^{+}, \mathrm{F}^{-}, \mathrm{CH}_{3} \mathrm{COOH}\right.$, $\mathrm{CH}_{3} \mathrm{CH}_{2} \mathrm{OH}, \mathrm{HCHO}, \mathrm{CH}_{3} \mathrm{OH}$, and $\mathrm{CH}_{3} \mathrm{SH}$ ), which were all $10 \mu \mathrm{M}$ except for $\mathrm{CH}_{3} \mathrm{SH}(1.0 \mu \mathrm{M})$. The selectivity test results are shown in Figure 6B. Using the system shown in Figure 6A, only $3.0 \mathrm{ppm}$ of $\mathrm{H}_{2} \mathrm{~S}$ made a high ratio of $\left[\left(\mathrm{E}_{650} / \mathrm{E}_{520}\right)_{\text {Blank }}\right.$ $\left.\left(\mathrm{E}_{650} / \mathrm{E}_{520}\right)_{\text {sample }}\right] /$ Max, and the AuNPs solution remained red in color (photograph in Figure 6B). The proposed method can also be used to detect $\mathrm{SO}_{2}$ even in air containing little $\mathrm{H}_{2} \mathrm{~S}$ by using a wet $\mathrm{CuSO}_{4}$-filled absorption column (see Figure $\mathrm{S} 8$ in the Supporting Information). Finally, the interference of the potential coexistence of gases was also evaluated. Because of the redox reaction, the oxidizing gases of $\mathrm{NO}_{2}, \mathrm{Cl}_{2}$, and $\mathrm{SO}_{2}$ cannot coexist with $\mathrm{H}_{2} \mathrm{~S}$ in air. Therefore, in this interference experiment, $\mathrm{NO}_{2}, \mathrm{Cl}_{2}$, and $\mathrm{SO}_{2}$ were not included. Simply, $3.0 \mathrm{ppm}$ of $\mathrm{H}_{2} \mathrm{~S}$ was first diluted in the $\mathrm{N}_{2}$ containing $100 \mathrm{ppm}$ of $\mathrm{CO}_{2}$. Then, the obtained $\mathrm{H}_{2} \mathrm{~S}$ gas was bubbled into the TBST that contained some other dissolved gases $\left(\mathrm{SO}_{4}{ }^{2-}\right.$, $\mathrm{NH}_{4}^{+}, \mathrm{F}^{-}, \mathrm{CH}_{3} \mathrm{COOH}, \mathrm{CH}_{3} \mathrm{CH}_{2} \mathrm{OH}, \mathrm{HCHO}, \mathrm{CH}_{3} \mathrm{OH}$, and $\left.\mathrm{CH}_{3} \mathrm{SH}\right)$ at $10 \mu \mathrm{M}$ levels except for $\mathrm{CH}_{3} \mathrm{SH}(1.0 \mu \mathrm{M})$. The test results indicated these potential coexisting gases only have a tiny impact on the $\mathrm{H}_{2} \mathrm{~S}$ sensing (Figure 6B). The good selectivity can be attributed to the high affinity between $\mathrm{Au}$ and S. In addition, compared to some SMO and electrochemical sensors, this method is not affected by humidity. In general, the good selectivity implies that the proposed method could be used for on-site colorimetric detection of $\mathrm{H}_{2} \mathrm{~S}$ in a gas sample.

Application of $\mathrm{H}_{2} \mathrm{~S}$ Detection in Air. The application of the proposed method was investigated for the detection of $\mathrm{H}_{2} \mathrm{~S}$ in local air. All of the air samples were spiked with $\mathrm{H}_{2} \mathrm{~S}$ at different concentration levels in pre-evacuated air bags, and 10 $\mathrm{mL}$ of the samples was bubbled into our analytical system. The analytical results are shown in Table 1 . The detection of $\mathrm{H}_{2} \mathrm{~S}$ was tested by a standard addition method, and the recovery of
Table 1. Determination Results of a Simulated Air Sample ${ }^{a}$

$\begin{array}{ccccc}\text { sample } & \text { spiked/ppm } & \text { detected/ppm } & \text { RSD } / \% & \text { recovery/\% } \\ 1 & 0.50 & 0.56 & 3.0 & 112.1 \\ 2 & 1.00 & 1.08 & 2.7 & 108.0 \\ 3 & 1.50 & 1.40 & 5.2 & 93.3\end{array}$

${ }^{a}$ The standard deviation was obtained by three measurements.

the spiked $\mathrm{H}_{2} \mathrm{~S}$ ranged from $93.3 \%$ to $112.1 \%$. The results suggest that such a method is applicable to the quantification of $\mathrm{H}_{2} \mathrm{~S}$ in air.

\section{CONCLUSIONS}

In summary, we have developed a low-cost, on-site visual method for the detection of $\mathrm{H}_{2} \mathrm{~S}$ in air. This method is achieved based on the antiaggregation of AuNPs by regulating the surfaces of AuNPs. Due to the high affinity between $\mathrm{S}$ and $\mathrm{Au}$, the sensor exhibits good sensitivity and selectivity. The proposed method possesses many merits: 1) this method is low cost (see Table S2 in the Supporting Information), and the test procedure does not need an auxiliary apparatus, such as a pump, valve, and detector; 2) the method is simple to conduct, as it is a label-free sensor without any premodification for AuNPs; 3 ) the antiaggregation-based AuNPs assays could avoid false positives that originate from spontaneous particle aggregation; $^{50}$ and 4) the method is easily applied to on-site detection without using any instruments. In terms of methodology, though this sensor is not a direct detection method for gaseous $\mathrm{H}_{2} \mathrm{~S}$, the operation of both the capture and the sensing step in the same weak alkaline buffer makes the whole detection process very simple and coherent. This method may provide a new route for sensing other pollutants in a gas sample.

\section{ASSOCIATED CONTENT}

\section{S Supporting Information}

UV-vis spectra and photographs of AuNPs; Flowchart for the detection of $\mathrm{H}_{2} \mathrm{~S}$; Tables of the $\mathrm{H}_{2} \mathrm{~S}$ capture efficiency and the test consumption; Detection limit calculation; Synthesis of $\mathrm{NO}_{2}, \mathrm{SO}_{2}$, and $\mathrm{Cl}_{2}$. This material is available free of charge via the Internet at http://pubs.acs.org.

\section{AUTHOR INFORMATION}

\section{Corresponding Authors}

*E-mail: zhpchen@yic.ac.cn (Z.C).

*E-mail: lxchen@yic.ac.cn (L.C.).

\section{Notes}

The authors declare no competing financial interest.

\section{ACKNOWLEDGMENTS}

The research was financially supported by the Department of Science and Technology of Shandong Province (BS2009DX006), NSFC (No. 21275158), the Project-sponsored by SRF for ROCS and the 100 Talents Program of the CAS.

\section{REFERENCES}

(1) Banshi, D. Surface Plasmon Resonance-based Fiber Optic Hydrogen Sulphide Gas Sensor Utilizing $\mathrm{Cu}-\mathrm{ZnO}$ Thin Films. Phys. Chem. Chem. Phys. 2013, 15, 11868-11874.

(2) Pandey, S. K.; Kim, K. H.; Tang, K. T. A Review of Sensor-Based Methods for Monitoring Hydrogen Sulfide. TrAC, Trends Anal. Chem. 2012, 32, 87-99. 
(3) Tao, W. H.; Tsai, C. H. $\mathrm{H}_{2} \mathrm{~S}$ Sensing Properties of Noble Metal Doped $\mathrm{WO}_{3}$ Thin Film Sensor Fabricated by Micromachining. Sens. Actuators, B 2002, 81, 237-247.

(4) Lawrence, N. S.; Davis, J.; Compton, R. G. Analytical Strategies for the Detection of Sulfide: a Review. Talanta 2000, 52, 771-784.

(5) Mickelson, W.; Sussman, A.; Zettl, A. Low-power, Fast, Selective Nanoparticle-Based Hydrogen Sulfide Gas Sensor. Appl. Phys. Lett. 2012, 100, 173110.

(6) Munz, M.; Langridge, M. T.; Devarepally, K. K.; Cox, D. C.; Patel, P.; Martin, N. A.; Vargha, G.; Stolojan, V.; White, S.; Curry, R. J. Facile Synthesis of Titania Nanowires Via a Hot Filament Method and Conductometric Measurement of Their Response to Hydrogen Sulfide Gas. ACS Appl. Mater. Interfaces 2013, 5, 1197-1205.

(7) Wang, Y.; Yan, H. Solid Polymer Electrolyte-Based Hydrogen Sulfide Sensor. Sens. Actuators, B 2002, 87, 115-121.

(8) Liang, X.; He, Y.; Liu, F.; Wang, B.; Zhong, T.; Quan, B.; Lu, G. Solid-state Potentiometric $\mathrm{H}_{2} \mathrm{~S}$ Sensor Combining NASICON with $\mathrm{Pr}_{6} \mathrm{O}_{11}$-doped $\mathrm{SnO}_{2}$ Electrode. Sens. Actuators, B 2007, 125, 544-549.

(9) Wang, R.; Yu, F.; Chen, L.; Chen, H.; Wang, L.; Zhang, W. A Highly Selective Turn-on Near-Infrared Fluorescent Probe for Hydrogen Sulfide Detection and Imaging in Living Cells. Chem. Commun. 2012, 48, 11757-11759.

(10) Chen, S.; Chen, Z.; Ren, W.; Ai, H. Reaction-based Genetically Encoded Fluorescent Hydrogen Sulfide Sensors. J. Am. Chem. Soc. 2012, 134, 9589-9592.

(11) Stetter, J. R.; Penrose, W. R.; Yao, S. Sensors, Chemical Sensors, Electrochemical Sensors, and ECS. J. Electrochem. Soc. 2003, 150, S11-S16.

(12) Bakker, E. Electrochemical Sensors. Anal. Chem. 2004, 76, 3285-3298.

(13) Liu, J.; Lu, Y. A Colorimetric Lead Biosensor Using DNAzymeDirected Assembly of Gold Nanoparticles. J. Am. Chem. Soc. 2003, 125, 6642-6643.

(14) Yu, F.; Li, P.; Song, P.; Wang, B.; Zhao, J.; Han, K. An ICTBased Strategy to a Colorimetric and Ratiometric Fluorescence Probe for Hydrogen Sulfide in Living Cells. Chem. Commun. 2012, 48, 28522854.

(15) Zhang, D.; Jin, W. Highly Selective and Sensitive Colorimetric Probe for Hydrogen Sulfide by a Copper (II) Complex of Azo-dye Based on Chemosensing Ensemble Approach. Spectrochim. Acta, Part A 2012, 90, 35-39.

(16) Gu, X.; Liu, C.; Zhu, Y.-C.; Zhu, Y.-Z. Development of a BoronDipyrromethene- $\mathrm{Cu}^{2+}$ Ensemble Based Colorimetric Probe toward Hydrogen Sulfide in Aqueous Media. Tetrahedron Lett. 2011, 52, 5000-5003.

(17) Zhao, Y.; Zhu, X.; Kan, H.; Wang, W.; Zhu, B.; Du, B.; Zhang, $X$. A Highly Selective Colorimetric Chemodosimeter for Fast and Quantitative Detection of Hydrogen Sulfide. Analyst 2012, 137, 55765580 .

(18) Della Gaspera, E.; Guglielmi, M.; Agnoli, S.; Granozzi, G.; Post, M. L.; Bello, V.; Mattei, G.; Martucci, A. Au Nanoparticles in Nanocrystalline $\mathrm{TiO}_{2}-\mathrm{NiO}$ Films for SPR-Based, Selective $\mathrm{H}_{2} \mathrm{~S}$ Gas Sensing. Chem. Mater. 2010, 22, 3407-3417.

(19) Bailey, T. S.; Pluth, M. D. Chemiluminescent Detection of Enzymatically Produced Hydrogen Sulfide: Substrate Hydrogen Bonding Influences Selectivity for $\mathrm{H}_{2} \mathrm{~S}$ over Biological Thiols. J. Am. Chem. Soc. 2013, 135, 16697-16704.

(20) Montoya, L. A.; Pearce, T. F.; Hansen, R. J.; Zakharov, L. N.; Pluth, M. D. Development of Selective Colorimetric Probes for Hydrogen Sulfide Based on Nucleophilic Aromatic Substitution. J. Org. Chem. 2013, 78, 6550-6557.

(21) Wu, M.-Y.; Li, K.; Hou, J.-T.; Huang, Z.; Yu, X.-Q. A Selective Colorimetric and Ratiometric Fluorescent Probe for Hydrogen Sulfide. Org. Biomol. Chem. 2012, 10, 8342-8347.

(22) Jarosz, A. P.; Yep, T.; Mutus, B. Microplate-Based Colorimetric Detection of Free Hydrogen Sulfide. Anal. Chem. 2013, 85, 36383643.

(23) Grant, C. D.; Schwartzberg, A. M.; Norman, T. J.; Zhang, J. Z. Ultrafast Eectronic Relaxation and Coherent Vibrational Oscillation of
Strongly Coupled Gold Nanoparticle Aggregates. J. Am. Chem. Soc. 2003, 125, 549-553.

(24) Kelly, K. L.; Coronado, E.; Zhao, L. L.; Schatz, G. C. The Optical Properties of Metal Nanoparticles: the Influence of Size, Shape, and Dielectric Environment. J. Phys. Chem. B 2003, 107, 668677.

(25) Wang, Z.; Ma, L. Gold Nanoparticle Probes. Coord. Chem. Rev. 2009, 253, 1607-1618.

(26) Xia, F.; Zuo, X.; Yang, R.; Xiao, Y.; Kang, D.; Vallée-Bélisle, A.; Gong, X.; Yuen, J. D.; Hsu, B. B.; Heeger, A. J. Colorimetric Detection of DNA, Small Molecules, Proteins, and Ions Using Unmodified Gold Nanoparticles and Conjugated Polyelectrolytes. Proc. Natl. Acad. Sci. U. S. A. 2010, 107, 10837-10841.

(27) Pavlov, V.; Xiao, Y.; Shlyahovsky, B.; Willner, I. AptamerFunctionalized Au Nanoparticles for the Amplified Optical Detection of Thrombin. J. Am. Chem. Soc. 2004, 126, 11768-11769.

(28) Elghanian, R.; Storhoff, J. J.; Mucic, R. C.; Letsinger, R. L.; Mirkin, C. A. Selective Colorimetric Detection of Polynucleotides Based on the Distance-Dependent Optical Properties of Gold Nanoparticles. Science 1997, 277, 1078-1081.

(29) Li, H.; Rothberg, L. Colorimetric Detection of DNA Sequences Based on Electrostatic Interactions with Unmodified Gold Nanoparticles. Proc. Natl. Acad. Sci. U. S. A. 2004, 101, 14036-14039.

(30) Deng, H.; Xu, Y.; Liu, Y.; Che, Z.; Guo, H.; Shan, S.; Sun, Y.; Liu, X.; Huang, K.; Ma, X. Gold Nanoparticles with Asymmetric Polymerase Chain Reaction for Colorimetric Detection of DNA Sequence. Anal. Chem. 2012, 84, 1253-1258.

(31) Lee, J. S.; Han, M. S.; Mirkin, C. A. Colorimetric Detection of Mercuric Ion $\left(\mathrm{Hg}^{2+}\right)$ in Aqueous Media Using DNA-Functionalized Gold Nanoparticles. Angew. Chem. 2007, 119, 4171-4174.

(32) Daniel, W. L.; Han, M. S.; Lee, J.-S.; Mirkin, C. A. Colorimetric Nitrite and Nitrate Detection with Gold Nanoparticle Probes and Kinetic End Points. J. Am. Chem. Soc. 2009, 131, 6362-6363.

(33) Zhang, Z.; Zhang, J.; Qu, C.; Pan, D.; Chen, Z.; Chen, L. Label Free Colorimetric Sensing of Thiocyanate Based on Inducing Aggregation of Tween 20-Stabilized Gold Nanoparticles. Analyst 2012, 137, 2682-2686.

(34) Zhang, J.; Wang, L.; Pan, D.; Song, S.; Boey, F. Y.; Zhang, H.; Fan, C. Visual Cocaine Detection with Gold Nanoparticles and Rationally Engineered Aptamer Structures. Small 2008, 4, 1196-1200.

(35) Brent Hiskey, J.; Atluri, V. Dissolution Chemistry of Gold and Silver in Different Lixiviants. Miner Process. Extr. Metall. Rev. 1988, 4, 95-134.

(36) Jeffrey, M.; Anderson, C. A Fundamental Study of the Alkaline Sulfide Leaching of Gold. Eur. J. Miner. Process. Environ. Prot. 2003, 3, $336-343$.

(37) Morris, T.; Copeland, H.; Szulczewski, G. Synthesis and Characterization of Gold Sulfide Nanoparticles. Langmuir 2002, 18, $535-539$.

(38) Bourg, M. C.; Badia, A.; Lennox, R. B. Gold-Sulfur Bonding in 2D and 3D Self-Assembled Monolayers: XPS Characterization. J. Phys. Chem. B 2000, 104, 6562-6567.

(39) Frens, G. Controlled Nucleation for the Regulation of the Particle Size in Monodisperse Gold Suspensions. Nature 1973, 241, 20-22.

(40) Ghosh, S. K.; Pal, T. Interparticle Coupling Effect on the Surface Plasmon Resonance of Gold Nanoparticles: from Theory to Applications. Chem. Rev. 2007, 107, 4797-4862.

(41) Kinsela, A. S.; Denmead, O. T.; Macdonald, B. C.; Melville, M. D.; Reynolds, J. K.; White, I. Field-Based Measurements of Sulfur Gas Emissions from An Agricultural Coastal Acid Sulfate Soil, Eastern Australia. Soil Res. 2011, 49, 471-480.

(42) Jang, N. H. The Coordination Chemistry of DNA Nucleosides on Gold Nanoparticles as a Probe by SERS. Bull. Korean Chem. Soc. 2002, 23, 1790-1800.

(43) Chen, X.; Hu, Y.; Gao, J. Tautomers of 2-aminothiazole Molecules in Aqueous Solutions Explored by Raman, SERS and DFT Methods. J. Mol. Struct. 2013, 1049, 362-367. 
(44) Gao, X.; Zhang, Y.; Weaver, M. J. Adsorption and Electrooxidative Pathways for Sulfide on Gold as Probed by Real-time Surface-Enhanced Raman Spectroscopy. Langmuir 1992, 8, 668-672.

(45) Lustemberg, P.; Vericat, C.; Benitez, G.; Vela, M.; Tognalli, N.; Fainstein, A.; Martiarena, M.; Salvarezza, R. Spontaneously Formed Sulfur Adlayers on Gold in Electrolyte Solutions: Adsorbed Sulfur or Gold Sulfide? J. Phys. Chem. C 2008, 112, 11394-11402.

(46) Pienpinijtham, P.; Han, X. X.; Ekgasit, S.; Ozaki, Y. Highly Sensitive and Selective Determination of Iodide and Thiocyanate Concentrations Using Surface-Enhanced Raman Scattering of StarchReduced Gold Nanoparticles. Anal. Chem. 2011, 83, 3655-3662.

(47) Chen, Y. Y.; Chang, H. T.; Shiang, Y. C.; Hung, Y. L.; Chiang, C. K.; Huang, C. C. Colorimetric Assay for Lead Ions Based on the Leaching of Gold Nanoparticles. Anal. Chem. 2009, 81, 9433-9439.

(48) Li, Y.; Wu, P.; Xu, H.; Zhang, Z.; Zhong, X. Highly Selective and Sensitive Visualizable Detection of $\mathrm{Hg}^{2+}$ Based on Anti-Aggregation of Gold Nanoparticles. Talanta 2011, 84, 508-512.

(49) Inomata, Y.; Matsunaga, K.; Murai, Y.; Osada, K.; Iwasaka, Y. Simultaneous Measurement of Volatile Sulfur Compounds Using Ascorbic Acid for Oxidant Removal and Gas Chromatography-Flame Photometric Detection. J. Chromatogr. A 1999, 864, 111-119.

(50) Du, J.; Sun, Y.; Jiang, L.; Cao, X.; Qi, D.; Yin, S.; Ma, J.; Boey, F. Y.; Chen, X. Flexible Colorimetric Detection of Mercuric Ion by Simply Mixing Nanoparticles and Oligopeptides. Small 2011, 7, 14071411. 